\title{
PARQUES INFANTIS E COLÔNIAS DE FÉRIAS COMO ESPAÇOS/ TEMPOS DE EDUCAÇÃO DA INFÂNCIA (1930-1940)
}

\author{
Rosianny Campos Berto \\ Mestre em Educação Física pela Universidade Federal do Espírito Santo e professora substituta da mesma instituição.
}

\begin{abstract}
Amarilio Ferreira Neto
Doutor em Educação pela Universidade Metodista de Piracicaba e professor da Universidade Federal do Espírito Santo.
\end{abstract}

\section{Omar Schneider}

Doutor em Educação pela Pontifícia Universidade Católica de São Paulo e professor da Universidade Federal do Espírito Santo.

\begin{abstract}
Resumo
Este artigo objetiva compreender como se processa a educação da infância em espaços/tempos extraescolares nos anos de 1930 a 1940 no Brasil. Para tanto, utiliza como fontes dois periódicos da Educação Física com ampla circulação no País: a Revista de Educação Física (do Exército) e a Revista Educação Physica, que possuem variados conselhos sobre a educação infantil. O estudo apóia-se na História Cultural a fim de captar, pela via da materialidade dos impressos, o modo como os sujeitos que escreviam para os periódicos produziam e faziam circular prescrições sobre um ideal de educação das crianças. Conclui-se que tais espaços se destinavam à assistência e à recreação e, especialmente, à educação infantil, como forma de complementar a educação escolar e preparar as crianças para a época nova.

Palavras-chave: Parques Infantis - Colônias de Férias - Imprensa Periódica
\end{abstract}

\section{Introdução}

$\mathrm{E}$ ste artigo é fruto de um estudo ${ }^{1}$ que pretende investigar o modo como se processa a educação escolarizada ou não da infância entre os anos 1930 e 1940, tendo como direcionamento as representações intelectuais que circulavam em dois periódicos com ampla veiculação no País: a Revista de Educação Física (do Exército) e a revista Educação $\mathrm{Physica}^{2}$, nos quais é possível localizar uma gama variada de conselhos aos pais e professores sobre a infância e a educação da criança.

A primeira revista foi criada pelos militares da Escola de Educação Física do Exército (EsEFEx), em 1932, e circula, sob outras configurações, até os dias atuais, e a segunda tinha como representantes intelectuais civis formados, em sua maioria, nas Associações Cristãs de Moços (ACM) e pertencia a uma casa de edição, a Cia. Brasil Editora. Este periódico cessou a circulação em 1945. Assim, ambos eram representados por atores pertencentes a organismos que possuíam “[...] um domínio do tempo pela fundação de um lugar autônomo", onde o poder é sempre preliminar do saber

1 Trata-se da dissertação de mestrado desenvolvida no Programa de Pós-Graduação em Educação Física da Universidade Federal do Espírito Santo (UFES).

2 Esses periódicos fazem parte do acervo do Instituto de Pesquisa em Educação e Educação Física (PROTEORIA), localizado no Centro de Educação Física e Desportos da UFES. 
(CERTEAU, 2004, p. 99). Organismos que, pela via da estratégia, construíam um "saber próprio" e o colocavam à leitura.

Nesse direcionamento, esse recorte objetiva compreender o modo como se desencadeava a educação da infância em espaços extra-escolares, a dizer, especialmente, dos parques infantis e das colônias de férias, tendo em vista as finalidades educacionais que envolviam esses espaços, direcionadas aos propósitos de regeneração e nacionalização em voga nos anos 1930 a 1940, no Brasil.

O estudo insere-se nos preceitos da história cultural que, para Roger Chartier (1988, p. 27), “[...] tem por principal objecto identificar o modo como em diferentes lugares e momentos uma realidade social é construída, pensada, dada a ler”, o que sugere pensar uma história cultural do social, apontando que as formas e os processos produzem sentido e, assim “[...] as inteligências não são desencarnadas, e [...] as categorias aparentemente mais invariáveis devem ser construídas na descontinuidade das trajectórias históricas" (CHARTIER, 1988, p. 27).

Nessa direção, a utilização do impresso, como objeto privilegiado, parte de um modelo que o toma pela sua materialidade, que o entende como objeto cultural, pois, segundo Chartier (1988, p. 127), “[...] não existe nenhum texto fora do suporte que o dá a ler, [...] não há compreensão de um escrito, qualquer que ele seja, que não dependa das formas através das quais ele chega ao seu leitor".

Tal perspectiva de trabalho privilegia os suportes materiais nas suas formas impressas ou manuscritas, considerando o método como uma arqueologia dos objetos ${ }^{3}$. Essa forma de entendimento da pesquisa histórica é profícua por compreender a riqueza dos objetos culturais, uma vez que possibilita o uso de uma gama variada de fontes, as quais abrem caminhos e possibilidades para pensar as práticas, as instituições, os impressos, os novos referenciais teórico-metodológicos que compreendem a cultura como prática.

Para esta análise, alguns conceitos são fundamentais. $\mathrm{O}$ primeiro deles é a noção de representação. Das distintas possibilidades que os impressos oferecem para a investigação, esse conceito, no modo como é utilizado por Chartier (1988), propõe que existe, na relação com o mundo social,

[...] em primeiro lugar, o trabalho de classificação e de delimitação que produz as configurações intelectuais múltiplas, através das quais a realidade é contraditoriamente construída pelos diferentes grupos; seguidamente, as práticas que visam fazer reconhecer uma identidade social, exibir uma maneira própria de estar no mundo, significar simbolicamente um estatuto e uma posição; por fim, as formas institucionalizadas e objectivadas graças às quais uns 'representantes' (instâncias colectivas ou pessoas singulares) marcam de forma visível e perpetuada a existência do grupo, da classe ou da comunidade (CHARTIER, 1988, p. 23, grifo do autor).

Os modos como eram pensadas a infância, a educação das crianças em espaços extra-escolares e a Educação Física nesse sentido pelos diferentes grupos que escreviam para as revistas - militares e civis - ou, dizendo de outro modo, as representações que são dadas a ler acerca desses aspectos constituem a questão central deste artigo.

3 Termo proposto por Roger Chartier (1988). 
Na busca de precisar o objeto de estudo no campo da história cultural e da história da Educação Física, entendemos que a Revista de Educação Física (do Exército) e a revista Educação Physica, que circularam em período simultâneo, são meios capazes de dar a ver indícios que possibilitem pensar/repensar aspectos da história da Educação Física.

\section{A materialidade dos periódicos: saberes e prescrições}

A Revista de Educação Física (do Exército), que aponta como seu principal objetivo a "[...] causa do aperfeiçoamento racial, como fundamento de todo progresso e de todas as conquistas reservadas, no futuro, à glorificação da nossa gente", coloca-se como um órgão de difusão técnica que busca "[...] espalhar seu crédo que é um hino constante de confiança nos destinos da Pátria em que a Educação Física terá, certamente, uma influencia decisiva!" (ABREU, 1933, p. 1). A intenção de seus editores, então, é contribuir para a moralização, para a civilidade, propiciando o cultivo do corpo, fornecendo para isso meios científicos. Seu intento é colaborar, por meio da Educação Física, com a educação, "problema primacial do Brasil".

$\mathrm{Se}$, nas capas da revista, o esporte aparece de forma intensa, no seu interior, não acontece o mesmo. Diferentemente da revista dos civis, o esporte parece, até certo ponto, não ser o foco da atenção principal dos militares. $\mathrm{Na}$ maior parte dos casos em que ele aparece, pelo menos nos primeiros números da revista, circula voltando atenção maior às diferentes modalidades do atletismo, à natação, à esgrima, entre outros esportes praticados na EsEFEx. No entanto a ginástica é um tema que circula fortemente nesse periódico, tendo como fundamento o método francês. Voltada para adultos, jovens e crianças em idade escolar, além de bebês, ela assume formas variadas de aplicação.

Schneider (2003), ao estudar a revista Educação Physica, compreende que o seu projeto cultural estava circunscrito a seus objetivos, por meio dos quais os editores mostram a intenção de ser a voz autorizada a falar pela Educação Física nas diversas instâncias. Tendo em vista atingir o maior número possível de leitores, propõe uma amplitude de olhares. Com essa intenção, podemos vislumbrar uma diversidade de leitores que incluem técnicos esportivos, professores de Educação Física, pessoas ligadas à educação, governos, instituições privadas, entre diversos outros.

No editorial do primeiro número, sinaliza sua intenção de orientar a Educação Física nacional.

Procurando ser uma força nova nos domínios da educação physica, espera poder reunir todos os elementos mais representativos e de maior autoridade e competência, no justo desejo de tornar um bloco único e indissolúvel todas as pequenas e grandes parcellas de verdadeiros valores que se acham esparsas (EDUCAÇÃO Physica, 1932, p. 3).

Ao olhar para as temáticas que esses impressos colocaram em circulação, é possível visualizar algumas aproximações e diferenças entre eles. A análise dá a ver, de forma diferenciada para cada um deles, que os temas em circulação nas duas revistas, guardadas as devidas proporções, indicam projetos mais ou menos aproximados. Temas muito semelhantes são encontrados em ambos os periódicos. A revista Educação 
Physica é balizada, desde o início, pelo esporte, mas apresenta uma gama variada de outros temas, e a revista militar traz fortemente em suas páginas a presença da ginástica, contudo vai, aos poucos, se mostrando adepta dos esportes e esportivizando suas prescrições.

Com relação aos leitores visados para aquilo que veiculavam, as revistas sugerem os mesmos grupos de leitores, que incluem: professores de Educação Física, técnicos esportivos, leigos (pais e mães, homens e mulheres), pessoas ligadas a clubes esportivos e instituições privadas de ensino, treinadores, entre outros.

É possível também apreender que as idéias balizadoras dos dois periódicos os colocam em certa conformidade, ao nortearem o cultivo do corpo e os cuidados com ele, por uma visão modernizadora, civilizadora e regeneradora. Isso também é perceptível se for levada em conta a circulação dos atores entre essas revistas. Assim, para Ferreira Neto, Bermond e Maia (2003, p. 101), os projetos culturais das duas revistas e as prescrições que elas veiculavam indicam "[...] uma convivência material de militares e civis dentro do[s] impresso[s] de cordialidade, cooperação e complementaridade em favor da 'causa nacional da Educação Física". Sobre esse aspecto, Sirinelli (1996, p. 249), ao tratar de uma história dos intelectuais, diz que “[...] uma revista é antes de tudo um lugar de fermentação intelectual e de relação afetiva, ao mesmo tempo viveiro e espaço de sociabilidade", mas, simultaneamente, da produção de uma alteridade coletiva em relação aos demais grupos.

Tanto na revista Educação Physica como na Revista de Educação Física (do Exército), a finalidade é contribuir para o bem da nação, melhorando a raça, restaurando as energias corpóreas, fortalecendo os músculos e preparando, por meio de uma educação integral, os pilares de uma nação que fizesse frente àquelas mais desenvolvidas.

\section{Parques infantis e colônias de férias como espaços/tempos de educação das crianças}

Nos dois periódicos, foi possível agenciar matérias referentes a uma forma de educar as crianças fora do ambiente escolar. Essas formas de educação e de Educação Física são compreendidas como importantes devido ao fato de oferecerem representações sobre a infância, capazes de fornecer uma melhor compreensão das intenções editoriais que perpassavam as revistas em torno da formação das crianças.

As prescrições para a educação infantil, sob essa perspectiva, se direcionam não somente a professores, mas também a outros profissionais e aos pais. Ao tomar a escola como principal locus de formação das "almas infantis", compreendemos que essas representações prescrevem meios para uma preparação da criança para a vida escolar, ou para a Educação Física nesse âmbito, ou atuam no sentido de serem complementares à educação ocorrida na escola.

De modo geral, os artigos que versam sobre a Educação e a Educação Física, em espaços e tempos extra-escolares, foram tematizados nos dois periódicos.

$\mathrm{Na}$ Revista de Educação Física (do Exército), foi encontrado um total de 39 artigos sobre a Educação e Educação Física extra-escolares, e os temas foram os seguintes: eventos e políticas de assistência e educação da infância - sete artigos; colônias 
de férias e parques infantis - quatorze artigos; ginástica infantil - dez artigos; jogos - quatro artigos; esporte infantil - quatro artigos.

$\mathrm{Na}$ revista Educação Physica, somam-se um total de 64 artigos dentro dessa categorização, quase o dobro dos encontrados na revista anterior: jogos - doze artigos; educação no lar - vinte e dois artigos; colônias de férias e parques infantis - dez artigos; alimentação - sete artigos; esporte infantil - três artigos; ginástica infantil cinco artigos; assistência à infância - cinco artigos.

No primeiro periódico, os quatorze textos encontrados sobre colônias de férias e parques infantis ${ }^{4}$ começaram a ser publicados a partir de 1933, veiculando pelo menos um artigo por ano até 1942 . No caso da revista Educação Physica, somente aparecem dez artigos. A circulação desse tipo de prescrição começa mais tarde para esse periódico, a partir de 1936, não aparecendo nenhum texto com essa temática nos anos 1937, 1939 e 1940. Em 1944, é veiculado o último artigo relacionado ao tema.

$\mathrm{Na}$ Revista de Educação Física (do Exército), os textos circundam aspectos como: os materiais necessários ao funcionamento desses espaços, à sua organização e administração, à recreação e às formas de educação nos parques infantis e nas colônias de férias. No caso do periódico civil, detalham-se os objetivos desses espaços, suas formas de organização e materiais necessários.

Assim, na revista do Exército, no que tange à educação e à Educação Física extraescolares, o maior número de artigos selecionados diz respeito aos campos de jogos, colônias de férias e parques infantis, como espaços destinados à diversão, mas, especialmente, às finalidades educativas.

Um campo de jogo seria, assim, “[...] um complemento necessário à escola. Nele se aprende a brincar, a viver com alegria, predispondo o espírito para as mais arrojadas realizações" (REVISTA de Educação Física, 1933, p. 26). Desse modo, o brinquedo praticado nos campos de jogos teria forte influência na formação moral das crianças, sendo de grande utilidade ao pedagogo, pois nesse espaço as crianças vivem e, na escola, preparam-se para viver.

Num sentido próximo, a necessidade das colônias ou centros de férias é abordada em alguns textos. O capitão Laurentino Lopes Bonorino (1933, p. 14) define esses centros como "[...] organizações sociais que têm seus alicerces na educação física, na vida ao ar livre cheia de liberdade e movimento, vida de intimidade, de simplicidade e de bondade, onde a criança vai, não apenas para distrair-se e repousar, mas, sobretudo, para adquirir saúde física e moral”.

Os centros/colônias de férias, com os quais o Centro Militar de Educação Física colaborava, segundo o autor, preparando professores de Educação Física, eram espaços para educar as crianças. A escolha das crianças para esses centros seria realizada por um médico, a partir de fichas.

A Figura 1, que ilustra o texto de Bonorino na revista, exibe uma lição de Educação Física, na qual fica visível uma contradição com relação à liberdade de que

4 Os espaços educativos extra-escolares recebem, nesses textos, as mais diferentes denominações: campos de recreio, campos de jogos, parques infantis, praças de desportos, colônias de férias. Contudo, pelo fato de aparecerem, mais correntemente, as denominações "parques infantis" e "colônias de férias", esses termos foram adotados como representativos dos espaços de educação extra-escolares. 
fala o autor. A aula aqui ilustrada mostra a realização de exercícios direcionados militarmente.

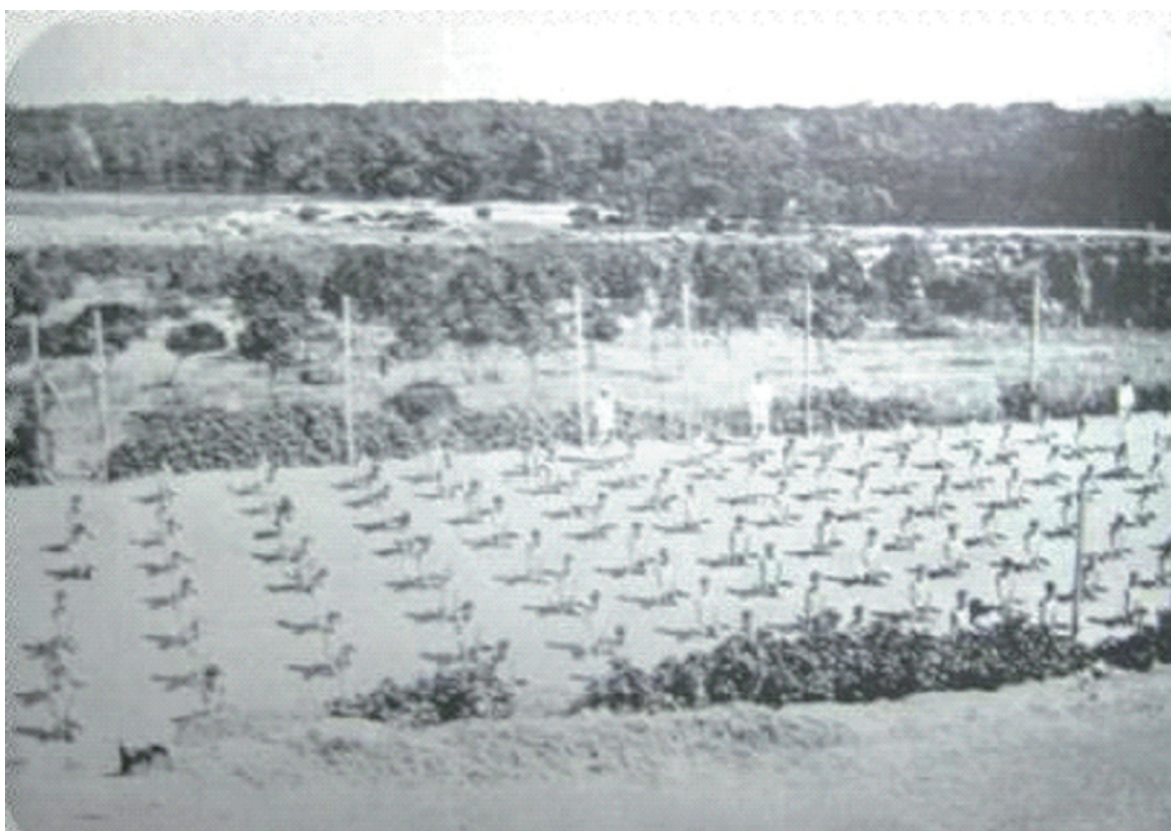

Figura 1 - Lição de Educação Física na colônia de férias

Fonte: Revista de Educação Física (do Exército), n. 9, 1933.

Nos artigos que versam sobre as colônias de férias são ainda sugeridas formas de organização das colônias, discriminando, detalhadamente, a estrutura física e o corpo profissional necessário. Entre esses últimos, é possível destacar enfermeiros e médicos. Alguns textos dispõem de exemplos de uma programação completa para as colônias, frisando aspectos da alimentação e da higiene (VUILLEMIN, 1934).

A existência de parques infantis é outra necessidade apontada pela revista. De acordo com Kuhlmann Júnior (2000), essas são instituições que começam a se estruturar no município de São Paulo, vinculadas ao Departamento de Cultura (DC), sob a direção de Mário de Andrade em 1935 e de Nicanor Miranda, chefe da Divisão de Educação e Recreio. Conforme o autor,

Uma característica distinta da instituição era sua proposta de receber no mesmo espaço crianças de 3 ou 4 a 6 anos, e de 7 a 12 fora do horário escolar. As idéias de Mário de Andrade sobre a criança e o Parque Infantil valorizam uma nova referência para a nacionalidade, com elementos do folclore, da produção cultural e artística, das brincadeiras e dos jogos infantis (KULHMANN JÚNIOR, 2000, p. 483).

Colombo (1938, p. 5), da Escola Nacional de Educação Física e Desportos, reclama a existência desses parques na Capital da República, pois, segundo ele, nas escolas públicas estaria relegada a segundo plano: "Quase não existem professores de educação física, os quais lhes ministrem exercícios para auxiliar o seu desenvolvimento e, quando existem, não podem seguir um plano metódico por diversas razões". 
Assim, ao denunciar a realidade das escolas naquele período, o autor enfatiza o espaço dos parques infantis como uma extensão da educação escolar, ou onde seriam supridas as falhas dessa educação. Assim, haver-se-ia de contribuir para tornar os indivíduos civilizados, eficientes, corteses, corajosos, responsáveis e, desse modo, "teremos contribuído enormemente para a regeneração da raça" (COLOMBO, 1938, p. 5).

Nicanor Miranda (1939), diretor da Divisão de Educação e Recreio do município de São Paulo, posiciona-se também a esse respeito e acentua uma necessidade de que se lançasse um olhar para a criança e que a compreendesse conforme suas peculiaridades.

\section{A escola não é, pois, o sistema ideal de cultura infantil. Um outro sistema precisa, não diremos substituí-la, mas completa-la. Um sistema que tome a criança como ela é, e a nossa complexa civilização como ela é, harmonizando os dois fatos de uma maneira científica e ao mesmo tempo humana [...]. Êsse sistema é o parque infantil (MIRANDA, 1939, p. 4).}

Nesse sentido, Faria (1999) discorre sobre a iniciativa de Mario de Andrade em São Paulo, à qual também estava ligado Nicanor Miranda. Essa iniciativa, com relação aos parques infantis, configurou-se, segundo a autora, em grandes contribuições para a construção de uma pedagogia da educação infantil.

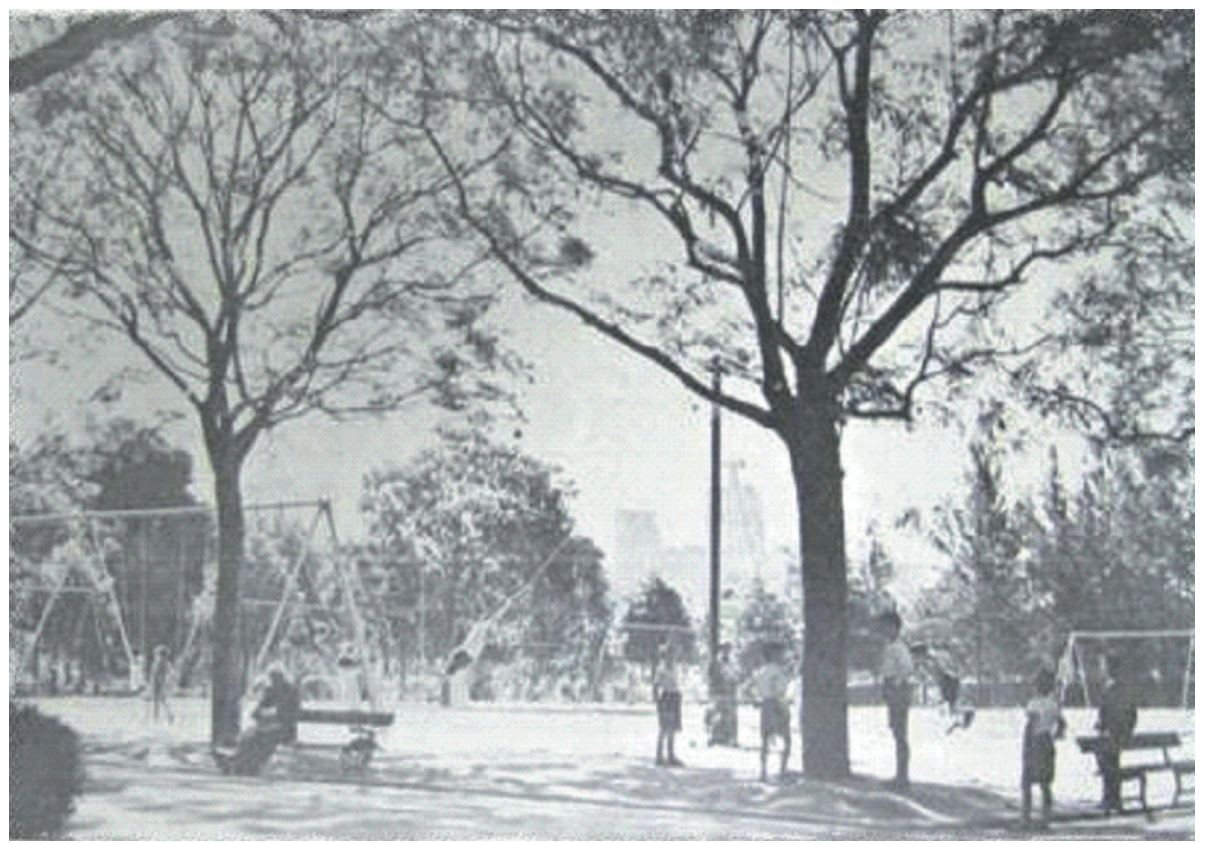

FIGURA 2 - Parques infantis

Fonte: Revista de Educação Física, n. 48, 1941.

Faria (1999) pontua ainda que, para atores como Mario de Andrade e Nicanor Miranda, a criança seria um ser portador da cultura de sua classe e, sendo assim, criados como uma alternativa às pré-escolas e aos espaços filantrópicos, os parques infantis baseavam-se na produção cultural (FARIA, 1999). 
[...] os filhos dos operários, contemplados, portanto, já sob a responsabilidade do município, com o direito à infância, isto é, com o direito ao não-trabalho, com o direito de brincar e de criar a cultura infantil, permanecendo crianças pelo menos enquanto estivessem no parque (FARIA, 1999, p. 70-71).

No entanto a liberdade do brinquedo, da vivência, da cultura infantil, tinha claros objetivos patrióticos, com os quais a Educação Física certamente poderia contribuir. Desse modo, dentro da escola ou nos parques infantis, ela "não só preencheria os fins biológicos, como psicológicos e morais; educação do corpo e do espírito e educação social, formando o homem de amanhã, vivificado pelo pensamento e pelo ideal, e disciplinado pela própria vontade" (MIRANDA, 1939, p. 10).

As reflexões de Chartier (1988) ajudam a pensar naquelas formas produtoras de sentido que colocam em associação as decisões dos autores dos textos a escrevê-los e as intenções editoriais, sempre presentes e dadas a ler nessa revista. Em torno da educação da infância, o periódico é regado de intenções informadoras e formadoras daqueles a quem seria destinado.

Assim, os objetivos do periódico militar, anunciados sempre nos editoriais, conforme assegura Abreu (1933, p. 1), tinham "um hino constante de confiança nos destinos da Pátria”, tinham seu foco claramente voltado para a educação das crianças, prescrita pelos autores, fosse para o meio escolar, fosse para os outros espaços educativos criados para atendê-las.

$\mathrm{Na}$ revista Educação Physica, onde os artigos sobre a educação e a Educação Física extra-escolares aparecem com mais intensidade - quase o dobro de artigos da revista militar - os textos referentes às colônias de férias e aos parques infantis aparecem em menor número.

Consideradas por Rodrigues (1936, p. 107) como “viveiros de bons cidadãos", o autor atribui a origem dos campos de recreio destinados às crianças à Alemanha. Apresenta como alguns dos precursores, Basedow e, posteriormente, Salgmann, Gutz-Mutz, Jahn e Spiess na Alemanha; Pestallozzi e Fallemberg na Suíça; Nachtegall na Dinamarca e Ling na Suécia, mas enfatiza que a América do Norte foi onde o movimento alcançou o desenvolvimento e a amplitude que se tornaram admiráveis: os "jardins de areia" nascidos em Boston, tornaram-se "playgrounds", que "constituem poderosíssima instituição, de reconhecida influencia na formação do corpo são e da mente sã da grande nação irmã” (RODRIGUES, 1936, p. 107).

$\mathrm{O}$ autor, ao falar sobre a presença do professor de Educação Física nesses espaços, aos quais chama ora de campos de recreios, ora de praças de desportos, assim se posiciona:

Cumpre ter-se na lembrança que os professores de praças de desportos se acham em contacto directo com as manifestações e expressões próprias à natureza infantil, e que, para as comprehender e orientar em bom caminho, seria mister conhecer antes de tudo a psychologia infantil, tanto como ou mais ainda que o professor de escola, e ter muito em conta que o menino o imita em tudo, sempre seguindo o exemplo do "heróe" (RODRIGUES, 1938, p. 76).

Mais uma vez, é possível perceber a relevância educativa que os espaços ditos de lazer e recreação das crianças recebiam e, desse modo, quais saberes seriam necessá- 
rios ao professor ou ao instrutor responsável pelo cuidado e educação das crianças que os freqüentavam.

Para falar de espaços e tempos prioritariamente destinados à infância, entram em cena as colônias de férias, lugares e momentos onde as crianças vão se refazer. Elas "devem descansar em um local aprazível, respirar livremente e melhorar as suas qualidades de nutrição por meio de uma boa alimentação" (EDUCAÇÃO Physica, 1942a, p. 33).

Circulam na revista alguns textos que denominam esses espaços de "colônias educacionais", que teriam uma finalidade diferente das colônias de férias comuns. Haveria aí um programa, com objetivo estritamente educacional, constando de exercícios físicos e recreação que deveriam ser ministrados por profissionais especializados. Nesse ambiente, seria dada também atenção aos jogos, aos banhos de sol, de mar, de chuveiro, de duchas, às leituras educativas, às aulas didáticas, sob forma de recreação e, ainda, haveria passeios, excursões, cinema, atividades artísticas e literárias, palestras, canto, dança, teatro. Todas as atividades com finalidade educativa (EDUCAÇÃO Physica, 1944).

Apesar da denominação dessa colônia e das finalidades educacionais salientadas no texto, não há grandes diferenças visíveis entre a colônia educacional e a chamada colônia de férias, como aparece na maior parte dos textos. De qualquer forma, os educadores que orientariam as crianças em colônias de férias "teem o dever de restituir aos pais, crianças não sòmente em melhores condições físicas, mas igualmente, em melhores condições morais" (EDUCAÇÃO Physica, 1942a, p. 34, grifo nosso), novos conhecimentos, bons hábitos de higiene e espírito alegre.

Num sentido próximo, os parques infantis, na revista Educação Physica, eram espaços destinados a uma assistência social à infância, com vistas a educar e recrear. Em São Paulo, atendiam às crianças de bairros operários e forneciam assistência médica, alimentar e dentária, preparando "cidadãos para a Pátria de amanhã, homens fortes física e moralmente, e não seres estiolantes, sem saude, fragmentos de homem e não homens. A educação de saude representa assim, dentro desse plano, uma preocupação contínua e primordial" (EDUCAÇÃO PHYSICA, 1942b, p. 40).

É sobre essa finalidade que Dante Costa (1943) recomenda a criação de parques infantis em cidades do interior do Brasil. O autor indica as formas detalhadas para a construção de parques, citando, inclusive, as dimensões, os tipos de aparelhos que eles deveriam ter, os cuidados estéticos com o parque, entre outros aspectos.

Kuhlmann Júnior (2000) lembra que é por volta de 1940 que os parques infantis se expandem para outras localidades do País, como o interior do Estado de São Paulo, Minas Gerais, Rio Grande do Sul, Recife, Bahia e Amazonas.

Linhales (2006) lembra que a construção de parques infantis, entre outros espaços de recreação/educação nas cidades para as crianças, mas também para jovens e adultos, já havia sido discutida no III Congresso Nacional de Educação, em 1929, num debate estabelecido pela Seção de Educação Sanitária.

O importante a observar sobre esses "espaços de recreação" para a criança - parques infantis, colônias de férias - é que são especialmente espaços de educação, de formação das almas. Os objetivos em torno da saúde e da higiene, de uma preparação intelectual, moral e física, eram fundamentos para a existência desses espaços. 


\title{
Considerações finais
}

A entrada nos periódicos, ao abordá-los como dispositivos materiais, permite alegar que as matérias que tinham por mote as temáticas referentes à educação da infância traziam como foco a "educação" do homem novo, o adulto de um futuro próximo e, portanto, a criança do presente, o homem e a mulher de amanhã. Desse modo, os investimentos na criança, que ganham grandes proporções nos finais do século XIX e na primeira metade do século XX, também colocam a infância como ponto de convergência dessas mesmas idéias.

A infância representada nos periódicos analisados é aquela sobre a qual estava depositada toda a esperança de um futuro melhor, em que a "belleza desse ideal de uma raça mais completa e mais nobre, desenvolvida ampla, simultaneamente, em todas as suas possibilidades" (EDUCAÇÃO Physica, 1934, p. 11) pudesse se tornar real. A esperança, assim, estava firme na elevação da nação para o plano de país desenvolvido e de seus filhos, para uma raça pura, com homens novos, civilizados e sempre prontos para o progresso.

Sendo assim, uma análise dos processos educativos da infância que ocorriam em espaços e tempos extra-escolares, a dizer dos parques infantis e das colônias de férias, aponta um olhar direcionado para as finalidades educacionais relacionadas com os propósitos de regeneração, civilização e nacionalização em voga nos anos 1930 a 1940, no Brasil.

Desse modo, os parques infantis e as colônias de férias destinavam-se à assistência e à recreação e, especialmente, à educação infantil, como forma de complementação da educação escolar ou como meio de preparação para a escolarização. As atividades nesses espaços, onde era proporcionado o contato com a natureza, eram norteadas pelas noções de saúde e higiene e de preparação intelectual, moral e física, de modo que as crianças se afastassem das más tendências e fossem mais bem preparadas para a época nova.

Parks and summer camps for children as educational places and times for child education in the 1930s and 1940s

\begin{abstract}
This article aims at understanding how child education took place in out-of-school places and times in the 1930s and 1940s in Brazil. Two Physical Education magazines with a large nationwide readership were used as research sources: the Army's Revista de Educação Física, and Educação Physica, both of which offered counseling on child education. With the support of cultural history, this study tries to capture how the individuals who wrote for these magazines produced and disseminated prescriptive information about a child education ideal. This study concludes that such places were destined to provide child assistance, recreation and, most of all, education which is supplementary to school education in order to prepare children for the new time.
\end{abstract}

Keywords: Parks for children - Summer Camps - the Press

Parques infantiles y colonias de vacaciones como espacios/tiempos de educación de la infancia (1930-1940)

\section{Resumen}

Este artículo pretende comprender cómo se procesaba la educación infantil en espacios/tiempos extraescolares en los años de 1930 a 1940 en Brasil. Utiliza como fuentes dos periódicos de Educación Física 
con amplia circulación en el país: La Revista de Educação Física (del Ejército) y La Revista Educação Physica, que tienen varios consejos sobre la educación infantil. Se apoya en la Historia Cultural para captar, a través de la materialidad de los impresos, el modo de cómo los sujetos que escribían para los periódicos producían y hacían circular prescripciones sobre un ideal de educación de niños. Se concluye que dichos espacios se destinaban a la asistencia y a la recreación y, especialmente, a la educación infantil, como complemento de la educación escolar y preparar a los niños para la época nueva.

Palabras-clave: Parques Infantiles - Colonias de Vacaciones - Publicaciones Periódicas

\section{Referências}

ABREU,J.R.T. de. Cruzada civica e eugenia do C.M.E.F. Revista de Educação Física, Rio de Janeiro, ano 2, n. 7, p. 1, abr. 1933.

BONORINO, L. L. São Paulo e os centros de férias. Revista de Educação Física, Rio de Janeiro, n. 9, jun. 1933.

CERTEAU, M. de. A invenção do cotidiano: 1 . artes de fazer. 10. ed. Petrópolis, RJ: Vozes, 2004.

CHARTIER, R. História cultural: entre práticas e representações. Lisboa: Difel, 1988.

COLOMBO, A. O Rio necessita de parques infantis. Revista de Educação Física, Rio de Janeiro, ano 6, n. 40, p. 5, jul. 1938.

COSTA, D. Parques infantis para cidades do interior. Revista de Educação Física, Rio de Janeiro, n. 75, p. 30-31, jul./ago. 1943.

EDUCAÇÃO Physica. Editorial, Rio de Janeiro, n. 1, p. 3, [s.m.] 1932.

. Editorial, Rio de Janeiro, n. 4, p. 11, mar. 1934.

. Campo e colônias de férias: alguns conselhos práticos: objetivos de uma colônia de férias. Rio de Janeiro, n. 70, p. 33-34, nov. 1942a.

. Parques infantis, Rio de Janeiro, n. 63, p. 38-40, mar./abr. 1942b.

. Colônias de férias e colônias educacionais, Rio de Janeiro, n. 78, p. 18-22, abr. 1944.

FARIA FILHO, L. M. Processo de escolarização no Brasil: algumas considerações e perspectivas de pesquisa. In: MENEZES, M. C. (Org.). Educação, memória, história: possibilidades, leituras. Campinas, SP: Mercado de Letras, 2004. p. 521-544.

FARIA, A. L. G. de. A contribuição dos parques infantis de Mário de Andrade para a construção de uma pedagogia da educação infantil. Educação E̊ Sociedade, Campinas, ano 20, n. 69, dez. 1999.

FERREIRA NETO, A.; BERMOND, M. T.; MAIA, E. de M. Revista de Educação Física: ciclo de vida, seção unidade de doutrina e lição de educação física (1932-2002). Revista Movimento, Porto Alegre, v. 9, n. 1, jan./abr. 2003. 
KUHLMANN JÚNIOR, M. Educando a infância brasileira. In: LOPES, E. M. T.; FARIA FILHO, L. M. de; VEIGA, C. G. 500 anos de educaşão no Brasil. Belo Horizonte: Autêntica, 2000. p. 469-496.

LINHALES, M. A. A escola, o esporte e a "energização do caráter": projetos culturais em circulação na Associação Brasileira de Educação: 1925-1935. 2006. Tese (Doutorado em Educação) - Faculdade de Educação, Universidade Federal de Minas Gerais, Belo Horizonte, 2006.

MADEIRA, A. Colônia de ferias. Revista de Educaşão Física, Rio de Janeiro, ano 2, n. 11, p. 18-19, out. 1933.

MIRANDA, N. O significado de um parque infantil em Santo Amaro. Revista de Educą̧ão Física, Rio de Janeiro, ano 7, n. 46, p. 3-5, out. 1939.

REVISTA de Educação Física. Campos de jogos: material. Rio de Janeiro, ano 2, n. 7, p. 26-27, abr. 1933.

1937.

. Organização de um campo de jogos. Rio de Janeiro, ano 5, n. 37, p. 3-5, dez.

RODRIGUES, J. Praças de esportes: origens dos campos de recreio. Educaşão Physi$c a$, Rio de Janeiro, n. 5, p. 107-108, abr. 1936.

RODRIGUES, J. J. A construção de praças de desportos. Educaşão Physica, Rio de Janeiro, n. 24, p. 75-76, nov. 1938.

SCHNEIDER, O. A revista Educação Physica (1932-195): estratégias editoriais e prescrições educacionais. 2003. 342 f. Dissertação (Mestrado em Educação) - Programa de Estudos Pós-Graduados em Educação: História, Política, Sociedade, Pontifícia Universidade Católica de São Paulo, São Paulo, 2003.

SIRINELLI, J. F. Os intelectuais. In: RÉMOND, R. (Org.). Por uma história política. Rio de Janeiro: Ed. UFRJ, 1996. p. 231-269.

VUILLEMIN, L. Colônias de férias. Revista de Educaşão Física, Rio de Janeiro, ano 2, n. 14, p. 10-12, jan. 1934.

Recebido: 29 de setembro 2008

Revisado: 24 de novembro 2008

Aprovado: 27 de novembro 2008

Endereço para correspondência

rosianny@proteoria.org 